\title{
Administrator calls for global health credentialing
}

$\mathrm{T}$

here's a need to establish a global health credentialing system that expedites physician migration and credentialing around the planet, says a Canadian medical school administrator.

"Why don't we have a system of accrediting medical schools?" asks Dr. Sarita Verma, vice- dean of postgraduate medical education at the University of Toronto in Toronto, Ontario. "We want to facilitate ease of traffic around the world."

"I just don't want people to be able to come here," she adds. "I want our people to be able to go elsewhere and there are just as many barriers to go to South Africa for Canadian doctors as there are for a South African doctor to come here.'

With increased global migration, and with nations actively recruiting overseas doctors to deal with domestic physician shortages, the current medical education checkerboard and the various long and complicated processes that different nations follow to assess medical credentials are becoming problematic.

That's compounded by the reality that there are an estimated 2073 medical schools operating within 170 nations and nothing in the way of an international body to enforce standards in medical education and training.

Verma says that it should be feasible to ascertain whether doctors are actually being trained differently and whether those differences actually have an impact on their capacity to treat patients. "Does that mean they provide care differently, or in the end, is a doctor a doctor?"

If it turns out that there are significant variations in the quality of medical training, then the solution lies in achieving some measure of consensus on appropriate standards that can be adopted internationally, Verma argues. "Is there a chance that we can actually come to one common consensus? ... If there are discrepancies, maybe it's hard work, but one of the things to do is

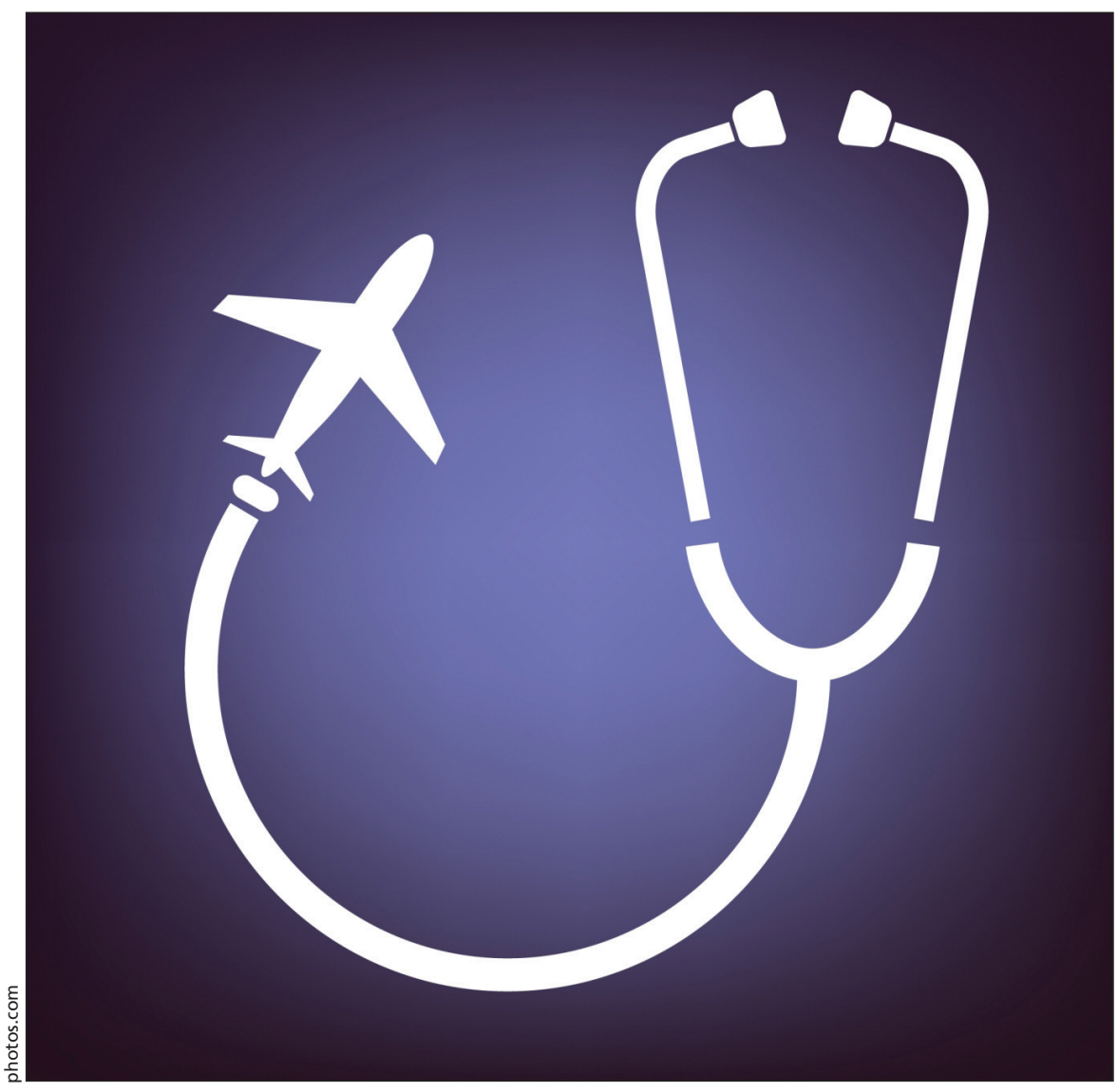

Significant patterns of migration among health care professionals were identified by experts from around the world at a conference on global health migration that was held jointly by the University of Toronto's Faculties of Medicine and Nursing in September 2008. Such patterns give rise to the question of establishing a system that would compare international medical education and training standards of doctors.

identify the gaps. ... There are major differences and I know there are, which is why the IMGs [International Medical Graduates] have difficulty. Let's address the gap."

International efforts to achieve some measure of standardization have thus far been largely confined to educational or promotional initiatives. The World Federation of Medical Education seeks to "enhance the quality of medical education worldwide. It has established global standards for medical education and guidelines for accreditation (www.wfme.org/).

But the Federation's standards are in no way binding. Nor does the organiza- tion, established in 1972, appear to seek to become an arbiter of credentials. It maintains that "the fundamental position that recognition or accreditation of medical education is a national responsibility. Consequently, WFME support the establishment of such systems and provide the necessary tools," a spokesperson stated in an email.

Similarly, the Foundation for Advancement of International Medical Education and Research sees its mission as supporting "the Educational Commission for Foreign Medical Graduates as it promotes international medical education through programmatic and research activities," (www.faimer.org/). 
The Foundation's vision is to expand its directory of processes used by medical schools to accredit doctors, says President Dr. John Norcini. The resulting database should provide information about the quality-control processes of accreditation and the various characteristics of medical schools, he adds. "I have to say that there are not many processes around that are as unexplored in the literature as accreditation is."

At present, nations are essentially left to their own inclinations in determining credentialing.

Doctors emigrating to North America are evaluated on an individual basis, by provincial, territorial or state regulating authorities, with few exceptions. A joint Canadian-American accrediting authority (the Committee on Accreditation of Canadian Medical Schools in Canada and the Liaison Committee on Medical Education in the US) smooths the process for medical graduates who wish to cross the 49th parallel. Most specialty training programs are considered equivalent, while medical graduates, with postgraduate medical training, are typically eligible to take national certification exams immediately, or with some additional training. Essentially, it has created a system in which Canadian regulatory authorities basically do not consider American medical graduates international medical graduates.

The situation is less clear-cut with respect to other nations. A decade ago, The Royal College of Physicians and Surgeons of Canada launched a jurisdictional accreditation program asking 200 nations about their programs were designed, operated, accredited and evaluated. More than 100 refused to participate. Dr. Andrew Padmos, the College's chief executive officer, sur-

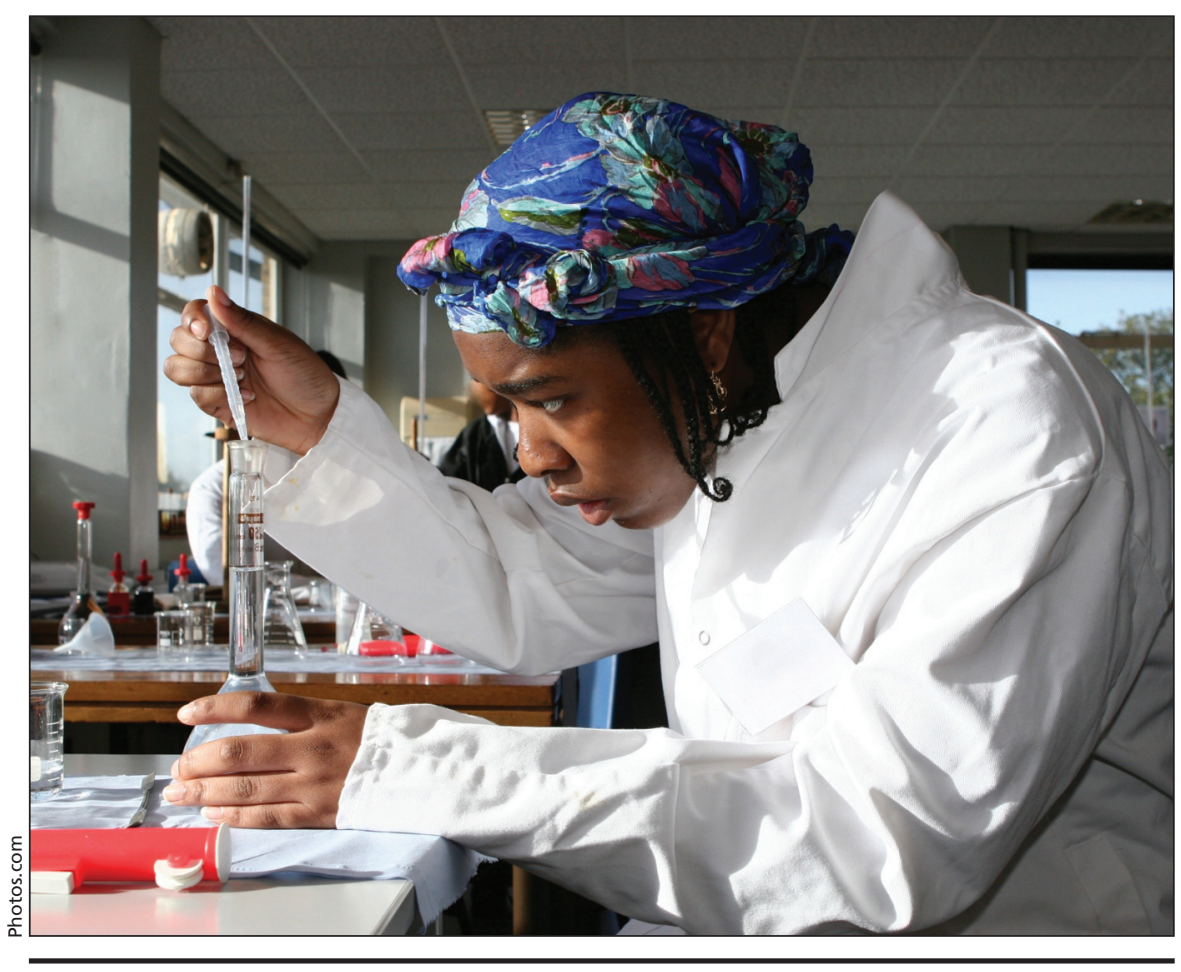

International efforts to achieve some measure of standardization of medical education and credentialing have thus far been largely promotional.

mises that was largely a product of a fear that doctors would leave their own jurisdictions to practise in Canada, or that some nations were not able to provide details in English or French. Ultimately, 29 institutions within 6 regions were accredited: the United Kingdom, Australia/New Zealand, South Africa, Malaysia, Hong Kong and southern Ireland.

Their graduates "can be considered for eligibility for The Royal College in Canada's exam, provided a detailed review of their training programs shows that they've met our criteria for the make-up of training," explains Padmos. "They have to be not only a graduate of that program, but the details of the program they studied have to be matched against Canadian requirements. But it is a shortcut and an accepted channel for evaluation of the graduates of those 29 programs."

A broader review was put on hold for several reasons: lack of participation, jurisdictions' inability to be evaluated against the criteria, and concern that the evaluation of additional programs compromised College fairness and access.

The review, though, is likely to resume as regulatory authorities appear eager to incorporate foreign trained doctors into the system more quickly, Padmos says. "It's the right thing to do." — Erin Driscoll, CMAJ

DOI:10.1503/cmaj.090127 